\title{
Iniciativas de avaliação do ensino fundamental em municípios brasileiros: mapeamento e tendências
}

\author{
ADRIANA BAUER \\ Universidade de São Paulo, São Paulo, SP, Brasil \\ SANDRA MARIA ZAKIA LIAN SOUSA \\ Universidade de São Paulo, São Paulo, SP, Brasil
}

JOÃO LUIZ HORTA NETO

Instituto Nacional de Estudos e Pesquisas Educacionais Anísio Teixeira, Brasília, DF, Brasil

RAQUEL DA CUNHA VALLE

Fundação Carlos Chagas, São Paulo, SP, Brasil

CLÁUDIA OLIVEIRA PIMENTA Universidade de São Paulo, São Paulo, SP, Brasil

\section{RESUMO}

Visando a mapear e caracterizar iniciativas relacionadas às avaliações em larga escala em desenvolvimento nos municípios brasileiros, desenvolveu-se uma pesquisa com abrangência nacional. Seus resultados são tratados no presente artigo, que se organiza em quatro seções. Inicialmente, apresenta-se uma síntese dos estudos já produzidos sobre a temática e, em seguida, explicitam-se os procedimentos metodológicos. Na terceira seção são discutidos os resultados obtidos por meio de survey, que abarcam informações obtidas de 4.309 municípios brasileiros. Por fim, são expostas conclusões acerca das concepções presentes nas avaliações propostas pelos municípios, bem como os usos dos resultados que as gestões desses entes federados fazem das diversas avaliações existentes, que evidenciam a consolidação da avaliação em larga escala como instrumento de gestão educacional nas municipalidades. 


\title{
ELEMENTARY SCHOOL EVALUATION INITIATIVES IN BRAZILIAN MUNICIPALITIES: MAPPING AND TRENDS
}

\begin{abstract}
Aiming to map and characterize initiatives related to large-scale assessments under development in Brazilian municipalities, a research with national coverage was developed. The results are addressed in this article, which is organized into four sections. Initially, it presents a synthesis of studies already carried out on the subject, and then methodological procedures are explained. In the third section, results obtained by the survey are discussed, with information collected from 4,309 Brazilian municipalities. Finally, conclusions are drawn about the concepts underlying evaluation methods proposed by each municipality, as well as the uses of results for educational management by the cities' authorities, showing that large-scale assessment programs are the main tool for education management across municipalities.
\end{abstract}

KEYWORDS

educational assessment; municipalities, education management; survey.

\section{INICIATIVAS DE EVALUACIÓN DE LA ESCUELA PRIMARIA EN LOS MUNICIPIOS BRASILEÑOS: MAPEO Y TENDENCIAS}

\section{RESUMEN}

Con el objetivo de mapear y caracterizar las iniciativas municipales relacionadas con evaluaciones a gran escala, se llevó a cabo una investigación en los municipios con cobertura nacional, cuyos resultados se abordan en este artículo, que se organiza en cuatro secciones. Inicialmente, se presenta la síntesis de estudios ya producidos sobre el tema bajo análisis y se explican a los procedimientos metodológicos. En la tercera sección se discuten los resultados obtenidos de la investigación, que cubren las manifestaciones obtenidas a partir de 4.309 de los 5.568 municipios investigados. Por último, se exponen las conclusiones acerca de los conceptos presentes en las evaluaciones propuestas por municipios y usos de los resultados que las gestiones municipales hacen de las diversas evaluaciones existentes, que muestran la consolidación de la evaluación a gran escala como una herramienta en la gestión educativa de los municipios.

PALABRAS CLAVE

evaluación de la educación; municipios; administración de la educación; survey. 


\section{INTRODUÇÃO}

Desde as primeiras iniciativas do governo federal de implantação da avaliação em larga escala da educação básica, nos anos 1990, apoiadas na Lei de Diretrizes e Bases da Educação Nacional e no Plano Nacional de Educação, gradualmente se somam proposições de avaliação concebidas por governos subnacionais.

No âmbito estadual, 20 dos 27 estados da federação já contam com propostas próprias de avaliação, sobre as quais alguns estudos se debruçam para elucidar seus contornos e repercussões na gestão educacional (Sousa e Oliveira, 2010; Bauer, 2006; 2010; Brooke, Cunha e Faleiros, 2011; Bauer e Reis, 2013, Horta Neto, 2013) ${ }^{1}$.

Com relação às iniciativas municipais, os estudos já divulgados trazem contribuições com base em um ou alguns contextos, no entanto não apoiam interpretações de tendências dominantes para o conjunto das municipalidades (Silva, 2005; Gomes, 2009; Gewehr, 2010; Marinho, 2010; Nascimento, 2010; Werle, 2010; Ferrarotto, 2011; Ovando, 2011; Gimenes e Silva, 2012; Pimenta, 2012; Gomes, 2012; Alavarse, Machado e Bravo, 2013; Bauer e Reis, 2013; Sousa; 2013; Werle, 2013; Côco, 2014; Duarte, 2014; Mardegan, 2014).

É nessa lacuna que se propôs o desenvolvimento de pesquisa que investigou iniciativas de avaliação educacional implementadas nos 5.568 municípios do território nacional ${ }^{2}$. Compreender como vêm se materializando e a que propósitos servem as avaliações nos contextos municipais torna-se relevante porque a avaliação se constitui, reconhecidamente, em mecanismo orientador e indutor da formulação de políticas e práticas educacionais.

O texto ora apresentado registra resultados obtidos com o estudo, antecedidos de informações sobre os caminhos metodológicos a que se recorreu para mapeamento e caracterização das iniciativas municipais. Destacam-se, nas indicações finais, revelações acerca de tendências observadas nas experiências analisadas, que suscitam questões para aprofundamento em pesquisas futuras.

\section{PROCEDIMENTOS DE ESTUDO}

O mapeamento das iniciativas municipais se deu por meio de survey que contou com a manifestação de dirigentes municipais de educação ou profissionais da rede de ensino por eles indicados, os quais responderam a um questionário, estruturado em três dimensões: interações do município com avaliações em larga escala propostas pelo governo federal e pelos governos estaduais; avaliações propostas pela rede municipal; e usos dos resultados das avaliações implantadas nos municípios. Procurou-se, ainda, obter informações que permitissem identificar os municípios.

1 Acre; Alagoas; Amazonas; Bahia; Ceará; Distrito Federal; Espírito Santo; Goiás; Minas Gerais; Mato Grosso do Sul; Pará; Paraíba; Paraná; Pernambuco; Piauí; Rio de Janeiro; Rio Grande do Sul; Rondônia; São Paulo; Tocantins.

2 Segundo o Instituto Brasileiro de Geografia e Estatística (IBGE), o Brasil contava, em 2013, com 5.570 cidades. No entanto, por sua natureza administrativa, Brasília e Fernando de Noronha foram excluídas do rol de cidades a serem contatadas na pesquisa. 
O levantamento de informações acerca das avaliações propostas pelas redes municipais contemplou diferentes focos: avaliação de alunos, avaliação institucional e avaliação de profissionais.

O total de respondentes variou para cada um desses focos, considerando-se que nem todos os municípios executam avaliações nos focos investigados. Para contemplar a diversidade de iniciativas municipais, o questionário permitia que os respondentes percorressem diferentes trajetórias ao respondê-lo, em decorrência da resposta negativa ou positiva às questões-chave.

O questionário, em formato eletrônico, foi aplicado utilizando-se a ferramenta Survey Monkey, que apoia a coleta de informações, codifica-as e consolida-as em um banco de dados, base para os processamentos e análises a seguir apresentados, que tratam de características e tendências presentes nas avaliações municipais e usos dos seus resultados para a gestão educacional.

Depois do pré-teste do instrumento ${ }^{3}$ e das devidas reformulações, o questionário foi enviado para 5.532 municípios $^{4}$, após contato prévio por telefone e/ou endereço eletrônico. Foram recebidas 4.309 respostas, o que representa $77,4 \%$ do total de municípios brasileiros. Além do alto percentual de retorno, raramente obtido com pesquisas dessa natureza, é oportuno registrar que todas as regiões do país foram representadas, como evidenciam os dados da Tabela 1.

Considerando-se o percentual de respostas obtidas, nota-se maior receptividade à pesquisa nas regiões Centro-Oeste, Sudeste e Sul, com $80 \%$ ou mais de retorno dos municípios.

Tabela 1 - Representatividades absoluta e relativa dos municípios que responderam ao survey, de acordo com a região geográfica [Base de dados da pesquisa e IBGE. Elaboração dos autores. 2016]

\begin{tabular}{l|c|c|c}
\hline \multirow{2}{*}{ Região } & Municípios & \multicolumn{2}{|c}{$\begin{array}{c}\text { Municípios que } \\
\text { brasileiros }\end{array}$} \\
\cline { 3 - 4 } & $\mathrm{n}$ & $\mathrm{n}$ & $\%$ \\
\cline { 3 - 4 } Norte & 450 & 323 & 71,8 \\
\hline Nordeste & 1.793 & 1.237 & 69,0 \\
\hline Centro-Oeste & 466 & 372 & 79,8 \\
\hline Sudeste & 1.668 & 1.395 & 83,6 \\
\hline Sul & 1.191 & 982 & 82,5 \\
\hline Total & 5.568 & 4.309 & 77,4 \\
\hline
\end{tabular}

3 O questionário foi composto por 44 questões, sendo 12 questões fechadas, 16 questões abertas e 16 questões mistas, ou seja, questões fechadas nas quais se conservava um espaço para a complementação da resposta.

4 Não se conseguiu nenhum tipo de contato, por telefone ou e-mail, com $36(0,6 \%)$ dos 5.568 municípios. Foram 1.223 os municípios que não responderam ao instrumento $(22 \%)$. 
Além do alto percentual de respostas obtidas, merece destaque o fato de que 10 estados tiveram percentual de respostas de $80 \%$ ou mais dos municípios que os compõem (RO, TO, PE, GO, MS, MG, SP, PR, SC, RS). A abrangência menor do estudo ocorreu em 4 estados, nos quais de 50 a $59 \%$ dos municípios responderam à pesquisa (AP, AM, MA, AL). Cabe destacar que, à exceção de Manaus, a pesquisa abrangeu todas as capitais de estados brasileiros.

Destacam-se, nas seções seguintes, contribuições trazidas com a pesquisa que ilustram tendências observadas nas iniciativas municipais de avaliação educacional.

\section{INICIATIVAS MUNICIPAIS DE AVALIAÇÃO EDUCACIONAL}

Além do registro da adesão às avaliações coordenadas pelo governo federal com destaque para a Provinha Brasil (participação de $97 \%$ dos municípios), a Prova Brasil (participação de $90 \%$ dos municípios) e a Avaliação Nacional da Alfabetização (participação de $90 \%$ dos municípios) —, 67\% dos municípios indicam compartilhar, também, das avaliações externas implantadas pelos governos dos estados a que pertencem. A essa constatação soma-se a proposição de iniciativas de avaliação próprias pelos municípios, declaradas por $37 \%$ dos respondentes $(n=1.573)$, o que representa cerca de $30 \%$ dos municípios brasileiros. Ainda, é oportuno registrar que $21 \%$ dos respondentes $(n=905)$ assinalaram pretender delinear uma proposta de avaliação própria, o que corresponde a $16 \%$ do total de municípios do país. Esses dados indicam que, gradativamente, amplia-se a coexistência, nas redes e nas escolas, de avaliações concebidas pelas diferentes instâncias governamentais.

Para conhecer o movimento de criação de avaliações municipais ao longo do tempo, foi perguntado aos gestores municipais qual o ano de implantação das iniciativas, obtendo-se resposta de 1.383 dos 1.573 municípios que realizam algum tipo de avaliação. Embora a primeira iniciativa date do início da década de 1980, observa-se que a criação de avaliações se intensifica a partir de 2005. Até 2004, 103 municípios implantaram ações próprias de avaliação. De 2005 a 2014, registra-se a criação de 1.280 novas iniciativas, mas outras avaliações podem ter sido implantadas depois de setembro de 2014, data de encerramento da coleta de dados (Gráfico 1).

Os 1.573 municípios que disseram ter criado propostas próprias de avaliação registraram que estas vêm sendo concebidas, em geral, por profissionais integrantes das redes de ensino, sejam técnicos (77\%), sejam professores e/ou gestores da rede (82\%). Aproximadamente 33\% dos municípios vêm recorrendo a assessorias externas (consultorias independentes, empresas ou universidades) para a definição do procedimento avaliativo adotado.

Seguem informações específicas sobre cada um dos focos em que incidem as iniciativas municipais de avaliação, para sua caracterização.

\section{AVALIAÇÃO DE ALUNOS}

Dos 1.573 municípios que responderam fazer algum tipo de avaliação própria, $1.302(82,8 \%)$ mencionaram a avaliação de alunos. Solicitados a registrar as razões que levaram a rede municipal de ensino a implantar avaliações próprias 
dos alunos, foram obtidas 3.753 indicações 5 . Conforme registros apresentados na Tabela 2, revela-se como principal motivação a necessidade de fazer o diagnóstico e o monitoramento do ensino e das aprendizagens. As indicações registradas convergem para iniciativas no âmbito das escolas, sejam aquelas voltadas para o diagnóstico de proficiências dos alunos, sejam as voltadas para o professor, que se propõem a acompanhar e aprimorar a prática pedagógica e a orientar a formação continuada.

Gráfico 1 - Número de municípios que criaram avaliações próprias, segundo o ano de sua implementação, dentre aqueles que têm algum tipo de avaliação municipal [Base de dados da pesquisa e IBGE. Elaboração dos autores. 2016]

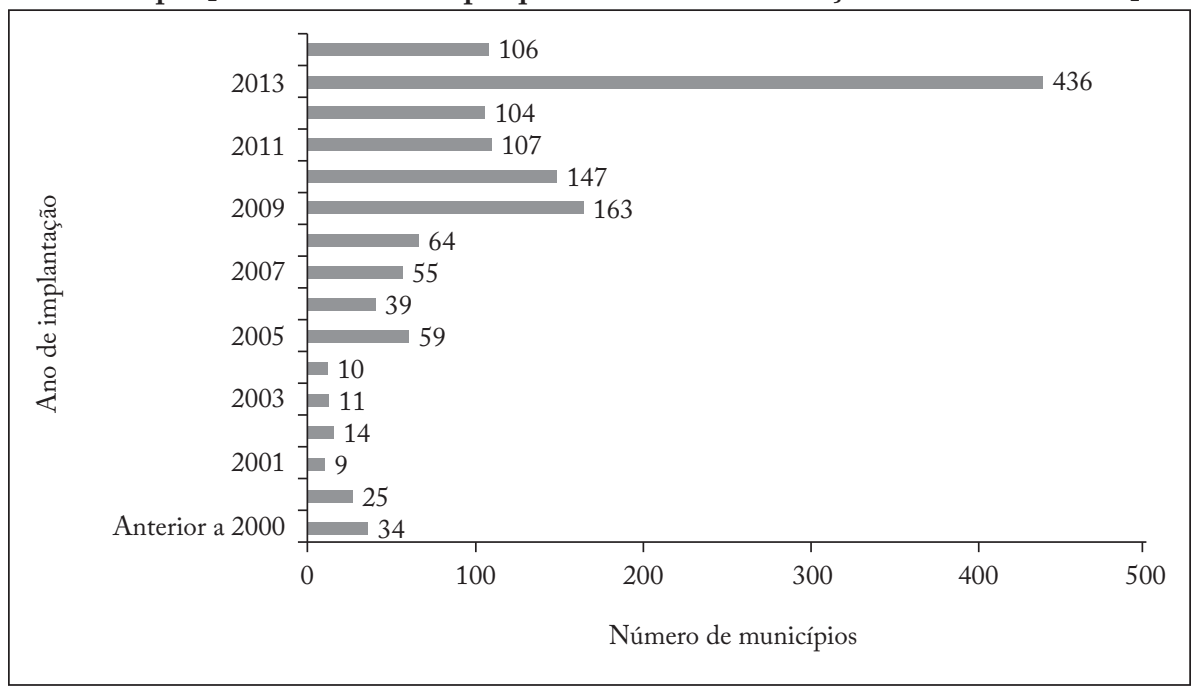

Tabela 2 - Distribuição de frequência dos motivos que levaram a rede municipal de ensino a implantar uma iniciativa própria de avaliação de alunos [Base de dados do survey. Elaboração dos autores. 2016]

\begin{tabular}{l|c|c}
\hline Razões & $\mathrm{n}$ & $\%$ \\
\hline $\begin{array}{l}\text { Diagnóstico, acompanhamento e monitoramento } \\
\text { do ensino e das aprendizagens }\end{array}$ & 1.609 & 43,0 \\
\hline Apoio ao gerenciamento educacional & 1.147 & 30,6 \\
\hline Melhoria de índices educacionais & 493 & 13,0 \\
\hline Outras razões & 93 & 2,5 \\
\hline Resposta não pertinente/não compreensível & 231 & 6,2 \\
\hline Total de indicações & 3.753 & 100,0 \\
\hline
\end{tabular}

5 Fala-se em indicações de respostas, pois, dentre os municípios que responderam à questão, alguns apontaram mais de três razões, enquanto outros deixaram de responder à questão. 
Além dessas razões, diversos registros fizeram menção a motivações relacionadas ao gerenciamento educacional, ao qual subjazem as ideias de planejamento de intervenções pedagógicas a partir de diagnóstico, controle e adequação curricular, proposição de atividades de formação continuada, avaliação do trabalho docente e mobilização de professores e alunos para a atividade educacional. Cerca de 30\% das indicações seguem essa direção.

As respostas revelam, ainda, a crença de que a avaliação de alunos pode induzir à melhoria de qualidade do ensino e de índices educacionais, como fluxo, evasão e repetência, bem como colaborar para o alcance das metas, havendo referências explícitas ao aumento do Índice de Desenvolvimento da Educação Básica (IDEB). A preocupação com o IDEB pode estar relacionada a programas do Ministério da Educação (MEC), como o Plano de Desenvolvimento da Escola (PDE-Escola), que visa ao apoio à gestão escolar, e os Planos de Ações Articuladas (PAR) ${ }^{6}$.

A Tabela 3 retrata as declarações dos respondentes sobre quais seriam os principais objetivos da avaliação de alunos. Nessa questão, era possível a escolha de até três das alternativas previamente especificadas e, ainda, o apontamento espontâneo de outros objetivos.

\section{Tabela 3 - Frequências observadas dos principais objetivos da avaliação de alunos promovida pela rede municipal de ensino \\ [Base de dados do survey. Elaboração dos autores. 2016]}

\begin{tabular}{|c|c|c|c|}
\hline \multicolumn{2}{|c|}{ Principais objetivos da avaliação de alunos } & $\mathrm{n}$ & $\%$ \\
\hline \multirow{3}{*}{$\begin{array}{l}\text { Acompanhamento } \\
\text { e monitoramento } \\
\text { da rede }\end{array}$} & Melhorar a aprendizagem dos alunos & 1.119 & 85,9 \\
\hline & $\begin{array}{c}\text { Melhorar o Índice de Desenvolvimento } \\
\text { da Educação Básica }\end{array}$ & 524 & 40,2 \\
\hline & Reduzir a taxa de repetência e/ou abandono & 427 & 32,8 \\
\hline \multirow{5}{*}{$\begin{array}{l}\text { Subsidiar o } \\
\text { planejamento } \\
\text { educacional }\end{array}$} & Definir prioridades para a gestão da educação municipal & 520 & 39,9 \\
\hline & Obter informações para a formação continuada & 450 & 34,6 \\
\hline & Rever propostas curriculares do município & 442 & 33,9 \\
\hline & Aprimorar os processos de gestão da rede municipal & 237 & 18,2 \\
\hline & $\begin{array}{l}\text { Obter informações para a premiação/bonificação } \\
\text { de escolas, gestores, professores e/ou alunos }\end{array}$ & 45 & 3,5 \\
\hline \multicolumn{2}{|c|}{ Divulgar os resultados das escolas para os pais e a comunidade } & 72 & 5,5 \\
\hline \multicolumn{2}{|c|}{ Outros objetivos } & 23 & 1,8 \\
\hline
\end{tabular}

6 O Plano de Desenvolvimento da Educação (PDE), apresentado pelo MEC em 2007, disponibilizou aos estados e municípios instrumentos de avaliação e implementação de políticas de melhoria da qualidade da educação básica, tendo como programa estratégico o Plano de Metas Compromisso Todos pela Educação. Com base no Plano de Metas, os estados e municípios passaram à elaboração de seus respectivos PAR, os quais contemplam o diagnóstico da situação educacional local e a elaboração do planejamento para o período 2011 a 2014, com base no IDEB de 2005, 2007 e 2009. 
Dentre as respostas, ressaltam-se, além da preocupação majoritária de melhoria da aprendizagem dos alunos, os objetivos de melhorar o IDEB e de obter informações para definir prioridades de gestão da educação municipal.

Poucos respondentes que assinalaram a alternativa "outros" e declararam espontaneamente outros objetivos indicados para a realização de avaliação de alunos pelo município reiteraram as razões para esse tipo de avaliação, já trabalhadas anteriormente. Além da ênfase no diagnóstico e no monitoramento do ensino e das aprendizagens, destacam-se o apoio à formação continuada de professores, à melhoria dos dados de fluxo dos alunos e à revisão das propostas curriculares.

Os dados sobre os anos/séries que têm sido focalizados pelas avaliações próprias das redes municipais de ensino permitem apreender maior preocupação com o acompanhamento dos alunos dos anos iniciais do ensino fundamental (Gráfico 2), já que é nesse segmento que se concentra o atendimento das redes locais. Entretanto, ainda que, segundo os dados, seja dada atenção um pouco maior às avaliações do $3^{\circ}$ e do $5^{\circ}$ anos desse segmento - o que poderia indicar a tendência de os municípios reproduzirem o desenho de avaliações federais e estaduais - , percebe-se que o segundo segmento do ensino fundamental também tem sido acompanhado.

Quanto às disciplinas usualmente abrangidas nas avaliações, observa-se que a tendência é avaliar os mesmos componentes curriculares já contemplados nos testes federais: matemática e língua portuguesa (com ênfase em leitura e interpretação de textos), ainda que haja, também, a menção da gramática como conteúdo avaliado (Tabela 4).

Observa-se o movimento dos municípios de avaliar outros componentes curriculares, como ciências, história e geografia. Fica a dúvida se tais componentes estão sendo avaliados de forma independente ou se fazem parte das avaliações

Gráfico 2 - Proporção de municípios que avaliam cada uma das séries do ensino fundamental, dentre as redes municipais que possuem avaliação de alunos [Fonte: Base de dados do survey. Elaboração dos autores. 2016]

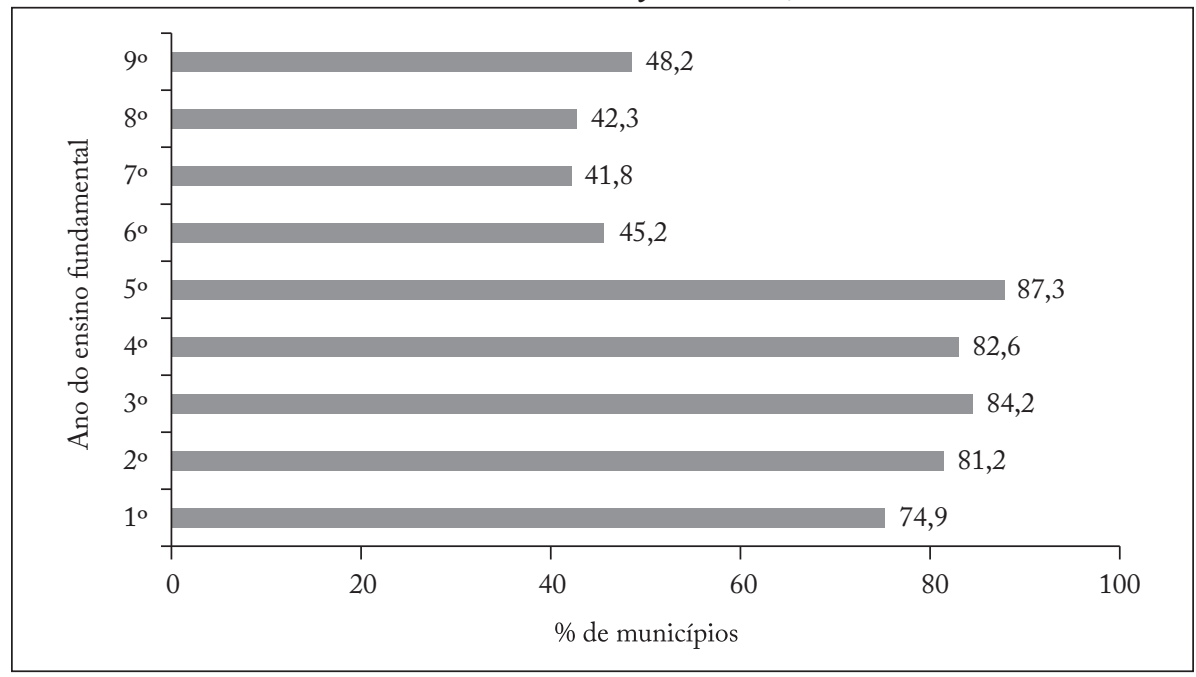


de português e matemática, já que muitos municípios utilizaram o espaço dedicado a outras disciplinas/áreas para esclarecer a natureza "interdisciplinar" das avaliações focadas na língua e na matemática.

De forma geral, as avaliações de alunos propostas pelas redes municipais utilizam provas e/ou testes cognitivos para aferir seu desempenho (90,6\%), que podem ou não vir acompanhados de questionários ou entrevistas com diversos atores (gestores, professores, alunos, pais ou responsáveis).

Os respondentes foram indagados sobre os documentos/materiais utilizados como referência para a definição do que avaliar. Na Tabela 5 é apresentada a frequência de resposta obtida para cada alternativa, previamente definida, já que se tratava de questão fechada.

Tabela 4 - Frequências observadas de cada uma das disciplinas/áreas do ensino fundamental avaliadas pelas redes municipais que possuem avaliação de alunos [Base de dados do survey. Elaboração dos autores. 2016]

\begin{tabular}{l|c|c}
\hline Disciplinas/áreas & $\mathrm{n}$ & $\%$ \\
\hline Leitura e interpretação de texto & 1.221 & 93,8 \\
\hline Matemática & 1.194 & 91,7 \\
\hline Gramática & 1.001 & 76,9 \\
\hline Redação & 948 & 72,8 \\
\hline Ciências & 626 & 48,1 \\
\hline História & 587 & 45,1 \\
\hline Geografia & 582 & 44,7 \\
\hline Artes & 424 & 32,6 \\
\hline Educação física & 416 & 32,0 \\
\hline Língua estrangeira & 377 & 29,0 \\
\hline Outras disciplinas/áreas & 157 & 12,1 \\
\hline
\end{tabular}

Tabela 5 - Frequência absoluta e relativa dos referenciais utilizados pelos municípios que possuem avaliação própria de alunos

[Base de dados da pesquisa e IBGE. Elaboração dos autores. 2016]

\begin{tabular}{l|c|c}
\hline $\begin{array}{l}\text { Referenciais utilizados nas } \\
\text { avaliações municipais de alunos }\end{array}$ & $\mathrm{n}$ & $\%$ \\
\hline Matrizes de referência da Prova Brasil & 1.097 & 84,3 \\
\hline Parâmetros curriculares nacionais & 1.077 & 82,7 \\
\hline Proposta curricular da rede municipal de ensino & 1.027 & 78,9 \\
\hline Conteúdos indicados pelos professores & 767 & 58,9 \\
\hline Matrizes de referência da avaliação estadual & 682 & 52,4 \\
\hline $\begin{array}{l}\text { Conteúdos indicados pelos profissionais da } \\
\text { Secretaria Municipal de Educação }\end{array}$ & 657 & 50,5 \\
\hline
\end{tabular}


A maioria dos municípios declarou utilizar as matrizes de referência da Prova Brasil e/ou documentos curriculares como os Parâmetros Curriculares Nacionais $(\mathrm{PCN})$ e as propostas curriculares da rede municipal de ensino. A intenção de adequar as avaliações às realidades municipais pode ser corroborada tanto pelo uso dos documentos curriculares municipais, apontada por cerca de 79\%, quanto pela consulta feita aos professores, prática assinalada por aproximadamente $59 \%$ dos respondentes.

Quanto aos procedimentos de tratamento e análise dos resultados obtidos na avaliação de alunos do ensino fundamental, foram contabilizadas 1.096 respostas, que se desdobram em 1.156 indicações distintas. A análise dos dados permite afirmar que, usualmente, os resultados obtidos pelos alunos nas provas são organizados por meio de tabulações e/ou elaboração de gráficos e apresentados em relatórios-síntese (579 indicações). Segundo alguns depoimentos, os dados são analisados coletivamente em reuniões, encontros e seminários realizados no âmbito das escolas e/ou da rede (112 indicações).

\section{AVALIAÇÃO INSTITUCIONAL}

Dos 1.573 municípios que afirmaram possuir avaliação própria, 977 $(62,1 \%)$ informaram implantar, na rede municipal de ensino, iniciativa de avaliação institucional.

A análise das razões apontadas por esses municípios para a proposição de uma avaliação institucional permite perceber que as motivações estão relacionadas a diferentes instâncias/componentes do processo educacional: a instituição escolar, o aluno, os profissionais de ensino, os resultados de desempenho da rede de ensino e a própria gestão da rede. Foi obtido um total de 2.384 indicações $^{7}$, como registrado na Tabela 6.

Tabela 6 - Distribuição de frequência dos motivos (expressos nos focos principais) que levaram a rede municipal de ensino a implantar uma iniciativa própria de avaliação institucional [Base de dados do survey. Elaboração dos autores. 2016]

\begin{tabular}{l|c|c}
\hline Principais focos das avaliações institucionais & $\mathrm{n}$ & $\%$ \\
\hline Foco na instituição escolar & 580 & 24,3 \\
\hline Foco na gestão da rede & 520 & 21,8 \\
\hline Foco nos resultados & 489 & 20,5 \\
\hline Foco no aluno & 449 & 18,8 \\
\hline Foco nos profissionais do ensino & 92 & 3,9 \\
\hline Outras razões & 64 & 2,7 \\
\hline Resposta não pertinente/não compreensível & 190 & 8,0 \\
\hline Total de indicações & 2.384 & 100 \\
\hline
\end{tabular}

7 Cabe lembrar que foi solicitado que os municípios indicassem espontaneamente até três razões que levaram à proposição desse tipo de avaliação, resultando no total de indicações referido. 
Dentre as razões que focalizam a instituição escolar, que abrangem o maior número de indicações $(\mathrm{n}=580)$, os depoimentos ressaltaram a necessidade de conhecer a realidade de cada escola, o desenvolvimento do trabalho pedagógico da instituição, bem como monitorar e acompanhar a consecução do projeto pedagógico, das propostas pedagógicas e/ou curriculares e dos planos escolares e dos investimentos. Com menor ênfase, foram citados o diagnóstico dos fatores intervenientes nos resultados e a ideia de que a avaliação institucional propicia a avaliação "da escola como um todo" e a autoavaliação do trabalho realizado. Destaca-se, ainda, o propósito de, por meio desse tipo de avaliação, buscar maior integração com a comunidade, traduzida em "escutar os pais", "levar os pais para a escola", identificar a percepção que pais e alunos têm da escola, permitir que os pais conheçam "a dinâmica da escola" e fortalecer mecanismos de gestão democrática, com referências ao conselho participativo. A ideia de que é possível subsidiar o trabalho do professor e dos gestores por meio da avaliação institucional também apareceu nos depoimentos classificados nessa categoria.

Nas razões que mencionam a avaliação institucional como estratégia para subsidiar a gestão da rede $(\mathrm{n}=520)$, tanto no âmbito da Secretaria Municipal de Educação, quanto no interior das escolas, foram recorrentes declarações que mencionaram: o subsídio à tomada de decisões com base no diagnóstico das realidades; o apoio ao planejamento e replanejamento; a proposição de ações/intervenções e metas a serem desenvolvidas e alcançadas; a realização de mudanças curriculares; a proposição de metas; o apoio à alocação de recursos etc. Também estão presentes nesse agrupamento a ideia de iniciativas voltadas para a prestação de contas e responsabilização (avaliar o trabalho de gestão, dar subsídios ao trabalho dos gestores escolares etc.) e a ideia de que a avaliação institucional permite "qualificar a gestão" e "melhorar a gestão administrativa e pedagógica". Muito citada é a ideia de rever ou propor alguma atividade de formação continuada aos professores, a partir dos resultados obtidos. Ainda que com menor ênfase, chamam atenção as declarações dos respondentes de que, com base na avaliação institucional, é possível estabelecer parâmetros/padrões de avaliação e de currículo para todas as escolas da rede.

As razões nas quais o foco de atenção recai sobre os resultados obtidos $(\mathrm{n}=489)$ mencionam a intenção de sua melhoria, com afirmações amplas (melhoria da escola, da educação, do ensino, da qualidade do ensino, do desempenho dos professores, dos processos de gestão, dos serviços prestados) ou por meio da indicação de aspectos específicos (melhoria dos resultados do IDEB, de dados de fluxo, de resultados dos alunos em língua portuguesa e matemática).

Um quarto agrupamento é constituído por razões que focalizam os alunos $(\mathrm{n}=449)$, sendo a avaliação institucional apontada como estratégia para a melhoria da aprendizagem, à medida que propicia a verificação, o diagnóstico, o acompanhamento e/ou monitoramento do desenvolvimento dos alunos, de seus rendimentos e aprendizagens. Essa ênfase no acompanhamento do desempenho e das aprendizagens aparece, por sua vez, associada à ideia de que é necessário conhecer as dificuldades, ou "pontos de partida", para adequar o ensino aos alunos. Nessa categoria, também foram incluídos os depoimentos que enfatizam ser necessário acompanhar os alunos para ver se estão se desenvolvendo de acordo com os descritores ou com 
o que é esperado pelos exames nacionais. Digna de nota, também, é a ideia de que a avaliação institucional serviria para preparar os alunos para outras avaliações (federais ou estaduais) ou para a competição do mercado.

Menor ênfase é observada em um agrupamento de razões que focalizam o professor $(n=92)$. Foram classificados nesse grupo os depoimentos que se referem à avaliação institucional como estratégia para propiciar a autoavaliação do professor, bem como a avaliação de seu desempenho. Citam-se, ainda, como motivações para a proposição desse tipo de avaliação, a necessidade de conscientizar/mobilizar/responsabilizar os professores pelo trabalho realizado e a importância de valorizá-los enquanto profissionais do ensino.

Outras razões fornecidas pelos municípios para justificar a adoção da avaliação institucional referem-se à ideia de atender à legislação vigente, à necessidade de comparar os resultados obtidos com os dados das avaliações oficiais ou, mesmo, de adequar a avaliação à realidade local. Ainda em relação aos resultados das avaliações oficiais, diversos depoimentos ressaltam que a opção por realizar avaliação institucional refere-se à necessidade de ter dados, em tempo hábil, para a proposição de intervenções. Com menor ênfase, aparece o discurso da necessidade de conhecer o trabalho da escola, atender às diferenças e garantir a equidade do ensino.

\section{AVALIAÇÃO DE PROFISSIONAIS DE ENSINO}

As questões relativas à avaliação de profissionais da educação focalizaram o levantamento de informações acerca de iniciativas direcionadas a professores e/ou gestores, buscando identificar também razões que motivaram essa ação, bem como evidências sobre o modo como vem sendo conduzida.

Dos 1.573 municípios que declararam fazer avaliação própria, 624 (39,7\%) afirmaram avaliar seus profissionais. Com base nesse dado, é possível supor que essa vertente de avaliação ainda não se disseminou como integrante da gestão educacional, embora a legislação vigente contemple dispositivos que remetem à normatização da avaliação docente, no âmbito dos estatutos e planos de carreira para o magistério público (Bauer e Sousa, 2013).

Aos municípios que registraram realizar alguma avaliação de seus profissionais - professores e/ou gestores - foi solicitado que indicassem até três razões que levaram à implantação dessa proposta de avaliação. Ao todo foram registradas 1.550 motivações para a adoção dessa medida ${ }^{8}$.

8 Visando a apreender as motivações dominantes que apoiaram as iniciativas municipais, cotejaram-se os registros feitos pelos respondentes com contribuições da literatura. Em especial, auxiliaram na identificação de categorias de respostas o estudo de Riegle (1987 apud Duke e Stiggins, 1997), que criou um marco conceitual para pensar o desenvolvimento do professorado e identificou cinco áreas de crescimento, e o estudo de Torrecilla (2007), que trata de propósitos da avaliação docente com base em estudo que caracterizou a estrutura e o funcionamento dos sistemas de carreira e a avaliação de desempenho docente em países da América e da Europa, tendo como foco os docentes da educação básica das escolas públicas. 
Os registros feitos pelos municípios foram, então, organizados em cinco categorias de resposta, que expressam propósitos da avaliação de profissionais da educação. A Tabela 7 apresenta o quantitativo de respostas em cada categoria. Alguns registros foram desconsiderados por não serem pertinentes à questão proposta $\mathrm{e}$ estão contabilizados como resposta "não pertinente/ não compreensível".

As razões mencionadas no primeiro agrupamento, que obteve o maior quantitativo de respostas, destacam a ideia de que as informações trazidas pela avaliação (como assiduidade, pontualidade, comprometimento, rotatividade etc.) podem subsidiar decisões administrativas concernentes à gestão de pessoal.

Segue-se, em termos quantitativos, um segundo grupo de depoimentos referentes à necessidade de estimular o desenvolvimento dos profissionais, considerando que sua avaliação pode contribuir para o crescimento individual no contexto da profissão docente, culminando em avanços na trajetória profissional. Um terceiro grupo, com mais de $20 \%$ de concentração de respostas, menciona razões ligadas ao aperfeiçoamento da atuação pedagógica e/ou do desempenho do professor, refletindo o pressuposto de que esse tipo de avaliação pode contribuir para a superação de dificuldades e para o aprimoramento do processo educativo, levando a novas práticas de ensino.

\section{USOS DOS RESULTADOS}

Quanto aos usos dos resultados das avaliações, foram apresentadas aos respondentes alternativas de respostas ${ }^{9}$, solicitando-se que assinalassem aquelas que correspondiam às práticas municipais usuais. Nessa questão era possível ser escolhida uma alternativa ou mais.

Tabela 7 -Distribuição de frequência dos motivos que levaram a rede municipal de ensino a implantar uma iniciativa própria de avaliação dos profissionais de ensino [Base de dados do survey. Elaboração dos autores. 2016]

\begin{tabular}{l|c|c}
\hline Razões & $\mathrm{n}$ & $\%$ \\
\hline Apoio à implantação de políticas educacionais e estratégias de gestão & 371 & 23,9 \\
\hline Estímulo ao desenvolvimento profissional & 341 & 22,0 \\
\hline Aperfeiçoamento da atuação pedagógica/desempenho profissional & 323 & 20,8 \\
\hline Melhoria de processos e de resultados & 253 & 16,3 \\
\hline Regulamentação da carreira docente & 185 & 11,9 \\
\hline Não pertinente ou não compreensível & 77 & 5,0 \\
\hline Total de indicações & 1.550 & 100 \\
\hline
\end{tabular}

9 As alternativas refletem aspectos dos usos que têm sido discutidos em diversas pesquisas já amplamente divulgadas como, por exemplo, Bauer (2010), Sousa e Oliveira (2010), Brooke, Cunha e Faleiros (2011) e Gimenes e Silva (2012). 
Para facilitar a análise, as respostas foram agrupadas em cinco grupos de usos, relacionados a: implantar iniciativas que visam a: incidir no currículo e nas práticas pedagógicas (Tabela 8); monitorar a rede de ensino (Tabela 9); divulgar resultados das avaliações para diferentes públicos (Tabela 10); apoiar a gestão

Tabela 8 - Frequências observadas dos usos dos resultados das avaliações relacionados à implantação de iniciativas que visam a incidir no currículo e nas práticas pedagógicas, declarados pelos municípios que responderam à pesquisa [Base de dados do survey. Elaboração dos autores. 2016]

\begin{tabular}{l|c|c}
\hline Usos dos resultados das avaliações & $\mathrm{n}$ & $\%$ \\
\hline Estimular as escolas a discutirem os resultados obtidos & 3.793 & 88,0 \\
\hline Planejar a formação continuada dos profissionais da rede & 3.623 & 84,1 \\
\hline Propor intervenções diferenciadas nas escolas & 3.578 & 83,0 \\
\hline Reestruturar o currículo das escolas & 3.134 & 72,7 \\
\hline Desenvolver material didático & 2.760 & 64,1 \\
\hline $\begin{array}{l}\text { Propor que as escolas produzam relatório } \\
\text { explicativo dos resultados obtidos }\end{array}$ & 2.026 & 47,0 \\
\hline Comprar material curricular estruturado e/ou apostilado & 1.582 & 36,7 \\
\hline
\end{tabular}

Tabela 9 - Frequências observadas dos usos dos resultados das avaliações relacionados ao monitoramento da rede de ensino, declarados pelos municípios que responderam à pesquisa [Base de dados do survey. Elaboração dos autores. 2016]

\begin{tabular}{l|c|c}
\hline Usos dos resultados das avaliações & $\mathrm{n}$ & $\%$ \\
\hline Identificar carências das escolas da rede & 3.642 & 84,5 \\
\hline Avaliar programas e ações desenvolvidos pela Secretaria & 3.413 & 79,2 \\
\hline Diagnosticar desigualdades entre as escolas da rede & 2.709 & 62,9 \\
\hline $\begin{array}{l}\text { Estabelecer metas de desempenho para as escolas, além daquelas } \\
\text { fixadas pelo Índice de Desenvolvimento da Educação Básica }\end{array}$ & 2.703 & 62,7 \\
\hline Reformular o Plano Municipal de Educação & 2.649 & 61,5 \\
\hline
\end{tabular}

Tabela 10 - Frequências observadas dos usos dos resultados das avaliações relacionados à divulgação das informações para diferentes públicos, declarados pelos municípios que responderam à pesquisa [Base de dados do survey. Elaboração dos autores. 2016]

\begin{tabular}{l|c|c}
\hline Usos dos resultados das avaliações & $\mathrm{n}$ & $\%$ \\
\hline $\begin{array}{l}\text { Fornecer informações sobre as escolas para } \\
\text { as famílias e a comunidade escolar }\end{array}$ & 3.669 & 85,1 \\
\hline Colocar os resultados em uma placa visível na frente da escola & 973 & 22,6 \\
\hline
\end{tabular}


de pessoal (Tabela 11); e implantar incentivos a escolas, alunos e/ou professores (Tabela 12). Os dados reportados nas tabelas referem-se às respostas afirmativas, em percentuais, para cada alternativa que compõe cada um dos agrupamentos, considerando-se as respostas dos 4.309 respondentes.

Quanto aos usos relacionados à implantação de iniciativas que incidam sobre o currículo e as práticas pedagógicas, percebe-se que mais de $80 \%$ dos respondentes indicaram utilizar os resultados para propor discussão sobre eles nas escolas, planejar a formação continuada dos profissionais da rede e propor intervenções diferenciadas às escolas.

Os dados disponibilizados na Tabela 9 reiteram a preocupação de monitorar as escolas, a qual já havia sido destacada quando os respondentes apontaram espontaneamente as razões que levaram a rede municipal de ensino a implantar avaliações próprias dos alunos. Destacam-se os depoimentos de municípios que afirmam utilizar os resultados para fazer o diagnóstico das carências das escolas da rede (84.5\%) e a avaliação de programas ou ações nela desenvolvidos $(79,2 \%)$.

As três alternativas mais assinaladas nesse grupo referem-se a ações de gestão e sugerem a intenção de buscar minorar as desigualdades internas da rede. Destaca-se, ainda, que 62,7\% dos respondentes assinalaram que usam as avaliações para estabelecer metas de desempenho para as escolas, além daquelas fixadas pelo IDEB. Compreender como essas metas são propostas e quais os objetivos inerentes a elas faz-se necessário, bem como investigar a afirmação de que as avaliações

Tabela 11 - Frequências observadas dos usos dos resultados das avaliações relacionados ao apoio à gestão de pessoal, declarados pelos municípios que responderam à pesquisa [Base de dados do survey. Elaboração dos autores. 2016]

\begin{tabular}{l|c|c}
\hline Usos dos resultados das avaliações & $\mathrm{n}$ & $\%$ \\
\hline Remanejar professores entre as escolas da rede & 921 & 21,4 \\
\hline Remanejar alunos entre as escolas da rede & 514 & 11,9 \\
\hline Remanejar gestores entre as escolas da rede & 493 & 11,4 \\
\hline Demitir gestores escolares & 259 & 6,0 \\
\hline
\end{tabular}

Tabela 12 - Frequências observadas dos usos dos resultados das avaliações relacionados à implantação de incentivos a escolas, alunos e/ou professores, declarados pelos municípios que responderam à pesquisa [Base de dados do survey. Elaboração dos autores. 2016]

\begin{tabular}{l|c|c}
\hline Usos dos resultados das avaliações & $\mathrm{n}$ & $\%$ \\
\hline Motivar as escolas a buscarem melhores resultados & 3.932 & 91,3 \\
\hline Dar algum prêmio aos alunos (computador, viagem etc.) & 574 & 13,3 \\
\hline $\begin{array}{l}\text { Dar algum prêmio às escolas (computadores, } \\
\text { recursos financeiros etc.) }\end{array}$ & 411 & 9,5 \\
\hline Oferecer bônus salarial aos profissionais das escolas & 271 & 6,3 \\
\hline
\end{tabular}


são usadas para reformular o Plano Municipal de Educação, assinalada por 61,5\% dos respondentes.

A Tabela 10 destaca informações sobre usos relativos à divulgação das informações para diferentes públicos. Os respondentes indicaram a intenção de fornecer informações sobre as escolas para as famílias e para a comunidade escolar (85\%), inclusive por meio da colocação de placas em frente às escolas (cerca de 23\%), ação polêmica que tem sido motivo de diversos debates entre educadores.

Dentre as menções que se referiram à utilização dos resultados obtidos nas diversas avaliações para a gestão de pessoal da rede (Tabela 11), a frequência maior de respostas relacionou-se ao remanejamento de professores entre escolas da rede. As outras três alternativas relacionam-se a ações de alocação de gestores e alunos e à possibilidade de demissão de gestores, a partir da análise dos resultados obtidos. Tais aspectos carecem de investigação complementar para que se compreenda o sentido que vêm assumindo na gestão de pessoal.

Por fim, no que se refere ao uso dos resultados para a distribuição de incentivos, quer às escolas e/ou seus profissionais, quer aos alunos, percebe-se, por meio da análise dos dados da Tabela 12, que tais práticas não são tão recorrentes como se poderia esperar pelo que vem sendo divulgado na literatura acadêmica. Os depoimentos ressaltam o incentivo ao alcance dos melhores resultados possíveis pelas escolas sem que, necessariamente, sejam atreladas a eles benesses de algum tipo. Mesmo entre os municípios que afirmam fazer algum tipo de premiação, percebe-se que esta é destinada prioritariamente aos alunos, com 13,3\% das indicações.

Ao analisar as alternativas globalmente, independentemente de seu agrupamento, nota-se que as mais escolhidas pelos respondentes apontam para o uso dos resultados para: "motivar as escolas a buscarem melhores resultados", com 91,3\% das respostas; "fornecer informações sobre as escolas para as famílias e a comunidade escolar" (85,1\%); "estimular as escolas a discutirem os resultados obtidos" (88,0\%); "identificar carências das escolas da rede" (84,5\%); "planejar a formação continuada dos profissionais da rede" (84,1\%); "propor intervenções diferenciadas nas escolas" (83\%); "avaliar programas e ações desenvolvidos pela Secretaria"(79,2\%); e, finalmente, indicação de uso para "reestruturar o currículo das escolas" (72,7\% dos respondentes). Caberia que outras pesquisas procurassem explorar os sentidos que assumem a proposição de intervenções diferenciadas nas escolas ou a reestruturação do currículo pela Secretaria, considerando que um mesmo enunciado pode ensejar práticas distintas.

Outros usos destacados são: desenvolver material didático (64\%) e reformular o Plano Municipal de Educação (61,5\%). Tais usos indicam ações no sentido de dar consequência ao processo de avaliação e, possivelmente, a preocupação de agir sobre a realidade, no sentido de superar possíveis problemas encontrados, com base nos resultados obtidos. Destaca-se que a alternativa que trata da compra de material curricular estruturado e/ou apostilado foi assinalada por 37\% dos respondentes. A estratégia de premiar alunos de acordo com os resultados obtidos nos testes foi assinalada por 13,3\% dos respondentes. Ainda com relação à premiação, $9,5 \%$ dos respondentes assinalaram que oferecem prêmios às escolas e $6 \%$ afirmaram proporcionar bônus salarial aos seus profissionais. Nesses casos parece estar subjacente a crença de que associar estímulos aos resultados dos testes pode induzir à melhoria do processo educacional. 
Vale destacar que as maiores frequências de resposta quanto aos usos dos resultados das avaliações incidem em expectativas de que esses venham a ser apropriados pelas escolas com vistas à busca de aprimoramento do trabalho escolar. Também é destaque a prática de estabelecer metas de desempenho além daquelas fixadas pelo IDEB, apesar de não haver informações sobre quais seriam elas nem a forma como estariam sendo discutidas ou fixadas. De toda forma, essa informação indica que o estabelecimento de metas tem sido valorizado como instrumento de gestão pelas secretarias de educação.

\section{INDICAÇÕES FINAIS}

As informações sistematizadas neste texto possibilitam retratar, em linhas gerais, como vem se dando a relação de municípios com a avaliação educacional e suscitam pontos que merecerão aprofundamento, não só no âmbito deste estudo, mas de outros que se delinearem como complementares. As contribuições trazidas para a discussão, relativas a contextos municipais, permitem evidenciar que a avaliação em larga escala vem se consolidando como instrumento de gestão educacional nas municipalidades. Parece haver correspondência entre as iniciativas municipais e as iniciativas do MEC, sejam aquelas relativas à avaliação em larga escala, sejam as relacionadas à criação de índices para aquilatar o desenvolvimento da qualidade educacional.

\section{REFERÊNCIAS}

Alavarse, O. M.; Machado, C.; Bravo, M. H. Avaliações externas e qualidade na Educação Básica: articulações e tendências. Estudos em Avaliação Educacional, São Paulo, v. 24, n. 54, p. 12-31, jan./abr. 2013.

Bauer, A. Usos dos resultados das avaliações de sistemas educacionais: iniciativas em curso em alguns países da América. Revista Brasileira de Estudos Pedagógicos, v. 91, p. 315-344, 2010.

. Usos dos resultados do SARESP: o papel da avaliação nas politicas de formação docente. Dissertação (Mestrado) - Faculdade de Educação, Universidade de São Paulo, São Paulo, 2006.

Bauer, A.; Reis, A. T. Balanço da produção teórica sobre avaliação de sistemas educacionais no Brasil: 1988 a 2011. In: Reunião Nacional Da ANPED, 36., 2013, Goiânia. Anais... 2013. Disponível em: <http://www.36reuniao.anped.org. br/pdfs_trabalhos_aprovados/gt05_trabalhos_pdfs/gt05_3375_texto.pdf $>$. Acesso em: 10 jun. 2014.

Bauer, A.; Sousa, S. Z. L. Avaliação e carreira docente: iniciativas da rede de ensino estadual de São Paulo. Revista e-Curriculum, São Paulo, v. 11, p. 201-215, 2013.

Brooke, N. P.; Cunha, M. A.; Faleiros, M. A Avaliação externa como instrumento da gestão educacional nos estados: Relatório Final, ago. 2011.

Côco, D. Avaliação externa da alfabetização: o PAEBES - Alfa no Espírito Santo. Tese (Doutorado em Educação) - Universidade Federal do Espírito Santo, Vitória, 2014. 
Duarte, A. B. A participação das escolas públicas de educação básica no SAEB: implicações nas formas de organização e desenvolvimento do trabalho escolar. Dissertação (Mestrado em Educação) - Universidade Federal de Santa Maria, Santa Maria, 2014.

Duke, D. L.; Stiggins, R. J. Más allá de la competencia mínima: evaluación para el desarrollo profesional. In: Millman, J.; Darling-Hammond, L. Manual para la evaluación del profesorado. Madri: Muralla, 1997.

Ferrarotto, L. Promase: análise de uma experiência de avaliação do sistema municipal de ensino de Amparo. Dissertação (Mestrado em Educação) - Universidade Estadual de Campinas, Campinas, 2011.

Gewehr, G. G. Avaliação da educação básica: politicas e práticas no contexto de escolas públicas municipais. Dissertação (Mestrado em Educação) - Pontifícia Universidade Católica do Paraná, Curitiba, 2010.

Gimenes, N. A. S.; Silva, V. G. Uso da avaliação externa por equipes gestoras eprofissionais docentes: um estudo em quatro redes de ensino público. Relatório de pesquisa. São Paulo: Fundação Carlos Chagas/Fundação Itaú Social, 2012.

Gomes, C. E. S. de L. Determinantes do baixo desempenho das escolas públicas municipais de Campos dos Goytacazes. Dissertação (Mestrado em Planejamento Regional e Gestão de Cidades) - Universidade Cândido Mendes, Campos dos Goytacazes, 2009.

Gomes, M. B. G. Monitoramento e Gestão do Ensino Fundamental: Práticas Escolares em Face de Politicas Indutoras. Dissertação (Programa de Pós-Graduação em Educação) Universidade Federal da Grande Dourados, Dourados, 2012.

Horta Neto, J. L. As avaliaçoes externas e seis efeitos sobre as políticas educacionais: uma análise comparada entre a União e os estados de Minas Gerais e São Paulo. Tese (Doutorado em Política Social) - Instituto de Ciências Humanas, Universidade de Brasília, Brasília,2013. IBGE. Perfil dos estados e municípios brasileiros 2014. Disponível em: <http://www. ibge.gov.br/home/estatistica/economia/perfilmunic/2014/>. Acesso em: 17 ago. 2017. Marinho, R. A. C. Políticas públicas de avaliação: a avaliação externa e a realidade educacional da microrregião de Januária-MG. Dissertação (Mestrado em Educação) Pontifícia Universidade Católica de Campinas, Campinas, 2010.

Mardegan, E. G. V. Avaliações externas e qualidade da Educação: repercussões das avaliações em larga escala nos discursos sobre as práticas em escolas da rede municipal de São Paulo. Dissertação (Mestrado em Educação) - Universidade Cidade de São Paulo, São Paulo, 2014.

Nascimento, G.P. do. SAEB: impactos de seus resultados e implicaçôes nas políticas públicas educacionais no município de Jaboticatubas/MG. Dissertação (Mestrado em Educação) Pontifícia Universidade Católica de Minas Gerais, Belo Horizonte, 2010.

Ovando, N. G. A avaliação na politica educacional de municípios sul-mato-grossenses. Dissertação (Mestrado em Educação) - Faculdade de Educação, Universidade Federal da Grande Dourados, Dourados, 2011.

Pimenta, C. O. As Avaliações Externas e o Trabalho de Coordenadores Pedagógicos: estudo em uma rede municipal paulista. 141 p. Dissertação (Mestrado) - Faculdade de Educação, Universidade de São Paulo, São Paulo, 2012. 
Silva, M. J. de A. O sistema mineiro de avaliação da educação pública: impactos na escola fundamental de Uberlândia. Dissertação (Mestrado em Educação) - Universidade Federal de Minas Gerais, Belo Horizonte, 2005.

Sousa, S. Z. Avaliação externa e em larga escala no âmbito do Estado brasileiro: interface de experiências estaduais e municipais de avaliação da Educação Básica com iniciativas do governo federal. In: BAuer, A.; GAtti, B. A. (Orgs.). 25 anos de avaliação de sistemas educacionais no Brasil: Implicações nas redes de ensino, no currículo e na formação de professores. Florianópolis: Insular, 2013. p. 61-85.

Sousa, S. Z.; Oliveira, R. P. Sistemas estaduais de avaliação: uso dos resultados, implicações e tendências. Cadernos de Pesquisa, São Paulo, v. 40, p. 793-822, 2010.

Torrecilla, J. M. Avaliação do desempenho e carreira docente: um estudo em cinquenta países da América Latina e Europa. In: O desafio da profissionalização docente no Brasil e na América Latina. Brasília: Consed, UNESCO, 2007.

Werle, F. O. C. (Org.). Avaliação em larga escala: foco na escola. São Leopoldo: Oikos; Brasília: Liber Livro, 2010.

. Experiências do estado do Rio Grande do Sul em destaque: interfaces com as políticas de avaliação federais. In: BAuer, A.; GATti, B. A.(Orgs.). 25 anos de avaliação de sistemas educacionais no Brasil: Implicações nas redes de ensino, no currículo e na formação de professores. Florianópolis: Insular, 2013. p. 193-210.

\section{SOBRE OS AUTORES}

Adriana Bauer é doutora em educação pela Universidade de São Paulo (USP). Professora da mesma instituição e pesquisadora da Fundação Carlos Chagas (FCC).

E-mail: adbauer@fcc.org.br; dri.bauer@usp.br

Sandra Maria Zákia Lian Sousa é doutora em educação pela Universidade de São Paulo (USP). Professora da mesma instituição.

E-mail: sanzakia@usp.br

João Luiz Horta Neto é doutor em educação pela Universidade de Brasília (UnB). Pesquisador do Instituto Nacional de Estudos e Pesquisas Educacionais Anísio Teixeira (Inep).

E-mail: jlhorta@gmail.com

Raquel da Cunha Valle é mestre em estatística pela Universidade de São Paulo (USP). Estatística da Fundação Carlos Chagas (FCC). E-mail: rvalle@fcc.org.br

Cláudia Oliveira Pimenta é doutoranda em educação pela Universidade de São Paulo (USP). Professora da rede estadual de São Paulo.

E-mail: pimentaclaudia@ibest.com.br 